\title{
Comparison of sublingual isosorbide dinitrate and Valsalva maneuver for detection of obstruction in hypertrophic cardiomyopathy
}

\author{
David Zemanek ${ }^{1,2}$, Pavol Tomasov ${ }^{1}$, Miloš Bělehrad², Katarína Hladká1, Jana Košt’álová2, \\ Tomáš Kára², Josef Veselka ${ }^{1}$
}

\begin{abstract}
${ }^{1}$ Department of Cardiology, $2^{\text {nd }}$ Medical School of Charles University and University Hospital Motol, Prague, Czech Republic

${ }^{2}$ International Clinical Research Center Brno, Brno, Czech Republic
\end{abstract}

Submitted: 25 June 2013

Accepted: 2 December 2013

Arch Med Sci 2015; 11, 4: 751-755

DOI: 10.5114/aoms.2015.47096

Copyright $\odot 2015$ Termedia \& Banach

\section{Abstract}

Introduction: A left ventricular outflow tract (LVOT) obstruction assessment with a provoking test should be a routine part of the evaluation of patients with hypertrophic cardiomyopathy (HCM). The aim of this study was to compare the utility of the Valsalva maneuver (VM) and sublingual spray application of isosorbide dinitrate (ISDN) for detection of an obstruction.

Material and methods: We prospectively evaluated 81 consecutive HCM patients without severe rest LVOT obstruction (defined as peak rest pressure gradient $(P G) \geq 50 \mathrm{~mm} \mathrm{Hg}$ ). We measured $P G$ at rest, during the VM, after sublingual ISDN spray, and during the VM after ISDN. An obstruction was defined as a PG $\geq 30 \mathrm{~mm} \mathrm{Hg}$.

Results: An obstruction was present in 15 patients (19\%) at rest (median and interquartile range of PG $16(7-26) \mathrm{mm} \mathrm{Hg})$, in 38 patients $(47 \%)$ during the VM (PG $28(12-49) \mathrm{mm} \mathrm{Hg}$ ), in 50 (62\%) patients after ISDN (PG $50(12-79) \mathrm{mm} \mathrm{Hg}$ ), and in 55 patients (68\%) during the VM after ISDN (PG 59 (20-87) $\mathrm{mm} \mathrm{Hg}$ ). The difference in occurrence of obstruction among different provoking tests was statistically significant for all comparisons $(p<0.001$, except for the comparison of the ISDN test with the VM during ISDN, $p=0.025$ ).

Conclusions: The ISDN test and the VM are useful screening methods for the detection of an HCM obstruction. Although ISDN appears to be more precise than the VM, the best option is a combination of both methods, which maximizes inducement of LVOT obstruction in patients with HCM.

Key words: hypertrophic cardiomyopathy, left ventricular outflow tract obstruction, nitrate, Valsalva maneuver.

\section{Introduction}

Hypertrophic cardiomyopathy (HCM) is mainly an autosomal dominant heart muscle disorder resulting from a mutation in genes for sarcomeric protein and characterized by myocardial hypertrophy with structural abnormalities. Other genetic mutations are less frequent. The clinical presentation is variable despite the same underlying genetic mutation [1]. Involvement of the left ventricle (LV) is more common, but the right ventricle is also frequently affected [2, 3]. According to current knowledge, more than half of HCM patients have a left ventricular out-

\author{
Corresponding author: \\ David Zemanek MD, PhD \\ Department of Cardiology \\ $2^{\text {nd }}$ Medical School \\ of Charles University and \\ University Hospital Motol \\ $\checkmark$ Uvalu 84, \\ 15021 Prague \\ Czech Republic \\ Phone: +420608921566 \\ E-mail: zejada@seznam.cz
}


flow tract (LVOT) obstruction. The obstruction of the LVOT is not always conditioned by HCM [4]. Nevertheless, it is an important pathophysiological component of HCM, and greatly depends upon not only the morphologic characteristics, but also hemodynamic conditions (ventricular load and contractile state); therefore, it can present with different levels of severity. Consequently, the use of a provoking test can increase the occurrence of LVOT obstruction up to $70 \%$ [5]. The obstruction evaluation is clinically relevant, since it may be associated with symptoms and can be managed using specific surgical and non-surgical interventions [6-8]. Many obstruction-provoking tests are able to increase the sensitivity of evaluations. The "gold standard" is exercise echocardiography, not only for its high sensitivity, but also for physiological simulation of real life situations [9]. However, this test takes time and requires special equipment.

In this study we sought to compare the utility of more undemanding tests such as sublingual spray application $(2.5 \mathrm{mg}$ ) of isosorbide dinitrate (ISDN) and the Valsalva maneuver (VM) for evaluation of LVOT obstructions in HCM.

\section{Material and methods}

Our tertiary cardiology center assessed 85 successive HCM patients between April 2010 and December 2011. The following criteria were observed in all of the patients who participated in the study: (1) wall thickness greater than $15 \mathrm{~mm}$, and (2) absence of significant valvular disease (with mitral regurgitation associated with HCM being the only exception), coronary artery disease, or any other specific, known cause of LV hypertrophy (e.g. glycogen storage disease, amyloidosis).

All patients enrolled in the study were examined by a clinician and underwent both an ECG and a two-dimensional echocardiogram (Sonos 7500, Philips, Andover, Massachusetts, USA). Through the use of standard transducer positions and a single operator, long- and short-axis echocardiography images were obtained; apical 2- and 4-chamber views were obtained in a similar fashion. Measurements of the LV parameters (wall thickness, end-diastolic, end-systolic diameter) and left atrium (dimension and calculated volume) were performed in either the parasternal long-axis or apical 4-chamber view. The American Society of Echocardiography's recommendations were adhered to in calculating the degree of hypertrophy. Simpson's rule was applied in a monoplane projection and used to calculate the volume of the LV and left atrium, as well as the LV ejection fraction [10]. Continuous-wave Doppler was used to measure the peak gradient, which was then calculated using a modified Bernoulli equation. A peak gra- dient measurement was performed during VM, following the sublingual application of $2.5 \mathrm{mg}$ of ISDN spray (Isoket spray, Schwartz Pharma AG, Germany), at the conclusion of every clinical evaluation. The VM was carried out during a standard echocardiogram procedure, and the ISDN application was performed after the measurement was obtained. There was a minimal chronological time difference of at least 5 min between the VM and ISDN tests. The peak LVOT gradient measurement was performed between 5 and 10 min following the ISDN application. Ten minutes after ISDN application, the next measurement was performed (during the VM). Long-term medications (e.g., $\beta$-blockers, calcium channel blockers) were not discontinued prior to testing.

\section{Statistical analysis}

For the purposes of the study, a significant obstruction was defined as a peak gradient greater than $30 \mathrm{~mm} \mathrm{Hg}$. The Wilcoxon signed-rank test was used to perform a statistical analysis of peak LVOT gradients. A $p$ value $<0.05$ was considered to be significant. McNemar's test was used to compare the occurrence of the obstruction at rest, during the VM, after ISDN and after ISDN/during VM. Multivariable logistic regression was performed for the following factors: age, LV end-diastolic diameter, LV ejection fraction, LV fractional shortening, maximal septal thickness, ratio of septal thickness to posterior wall thickness, LVOT peak gradient at rest, peak early diastolic mitral flow velocity, mitral annular motion and their ratio. All of the above-mentioned measurements were documented.

\section{Results}

Eighty-five patients suffering from HCM were prospectively evaluated. Due to having a rest peak gradient greater than $50 \mathrm{~mm} \mathrm{Hg}, 4$ patients were excluded from the study, as any additional provoked tests would have been risky and futile. Thus, a total of 81 patients were enrolled in the study. The clinical presentations of the patients are summarized in Table I. Fifteen patients (19\%) were observed to have a significant resting LVOT obstruction; this number increased to 38 patients (47\%) after the VM, and further increased to 50 patients (62\%) after ISDN. A combination of the VM and ISDN techniques resulted in an LVOT obstruction finding in 55 patients (68\%). All of the patients with negative combined testing results were also shown to have negative individual testing results. Among all of the groups, the occurrence of an LVOT obstruction was found to be statistically significant for all comparisons. The $p$ values for all comparisons were less than 0.001 , with the exception of the difference be- 
tween the ISDN test and the VM during ISDN, in which case the $p$ value was 0.025 .

If we changed the cut-off value for defining a clinically significant LVOT obstruction to that of a peak LVOT pressure gradient greater than $50 \mathrm{~mm} \mathrm{Hg}$, we found no obstructions present at rest. Due to the addition of the VM, an LVOT obstruction was observed in 20 (25\%) patients, and the use of ISDN resulted in an LVOT obstruction finding in 41 (50\%) patients. When both methods were used, an LVOT obstruction was observed in 47 (58\%) patients. The average peak LVOT gradients were $18.3 \mathrm{~mm} \mathrm{Hg}$ during "at rest" measurements, $33.6 \mathrm{~mm} \mathrm{Hg}$ during the VM, $50.5 \mathrm{~mm} \mathrm{Hg}$ after ISDN application, and $60.1 \mathrm{~mm} \mathrm{Hg}$ during the VM after ISDN. The median value for the peak atrest LVOT pressure gradient was $16 \mathrm{~mm} \mathrm{Hg}$, the VM and ISDN values were $28 \mathrm{~mm} \mathrm{Hg}$ and $50 \mathrm{~mm} \mathrm{Hg}$, respectively, and the value for the combination of both tests was $59 \mathrm{~mm} \mathrm{Hg}$. The differences among peak LVOT gradients were statistically significant among all measurements $(p<0.001)$. The results are summarized in Table II.

Multivariable logistic regression showed the peak at-rest LVOT gradient to be the only independent risk factor (odds ratio 14.06, $p=0.046$ ). Other parameters were not found to be independent risk factors. The application of ISDN was generally found to be safe, with only 1 patient experiencing temporary mild orthostatic hypotension with spontaneous recovery after $30 \mathrm{~min}$. No additional side effects of clinical importance were observed.

\section{Discussion}

Provoking tests are an important part of the evaluation of patients with hypertrophic cardiomyopathy. The search for LVOT obstruction has a clinical impact not only for the diagnosis of HCM, but especially for management of the disease. Exercise echocardiography is still considered the best method for evaluation of LVOT obstruction related to HCM and gives us important information for management of this disease, such as valvular disease (e.g. aortic stenosis) [11]. However, the procedure is time consuming and requires special equipment.
Table I. Baseline characteristics

\begin{tabular}{|lc|}
\hline Parameter & Result \\
\hline Patients, $n$ & 81 \\
\hline Age, mean \pm SD [years] & $53.4 \pm 14.4$ \\
\hline Sex, male (\%) & 63 \\
\hline Heart rate, mean \pm SD [beat/min] & $63.2 \pm 7.2$ \\
\hline Systolic pressure, mean \pm SD [mm Hg] & $129.8 \pm 1.9$ \\
\hline Diastolic pressure, mean \pm SD [mm Hg] & $81.5 \pm 8.4$ \\
\hline Body surface area, mean \pm SD [mm $\left.{ }^{2}\right]$ & $2.0 \pm 0.2$ \\
\hline LVEDD, mean \pm SD [mm] & $42.5 \pm 4.2$ \\
\hline Maximal wall thickness, mean \pm SD [mm] & $19.7 \pm 4.1$ \\
\hline Septum, mean \pm SD [mm] & $19.1 \pm 3.9$ \\
\hline Posterior wall, mean \pm SD [mm] & $13.5 \pm 2.1$ \\
\hline E, mean \pm SD [m/s] & $14.6 \pm 4.1$ \\
\hline E/A & $72.3 \pm 5.3$ \\
\hline Em, mean \pm SD [cm/s] & $1.0 \pm 0.4$ \\
\hline E/Em, mean \pm SD & $5.6 \pm 1.6$ \\
\hline LV ejection fraction (\%) & 37.2 \\
\hline LVH/BSA, mean \pm SD [mg/m²] & \\
\hline Clinical symptoms (\%) & \\
\hline HCM & \\
\hline
\end{tabular}

HCM - hypertrophic cardiomyopathy, LVEDD - left ventricular end-diastolic diameter, $E$ - peak velocity of early transmitral flow, A - peak velocity of late transmitral flow, Em-peak early diastolic velocity of septal mitral annulus, $L V$ - left ventricle, $L V H$ - left ventricular hypertrophy, BSA - body surface area.

Dobutamine echocardiography, as an alternative, is not as well established in hypertrophic cardiomyopathy as it is in aortic stenosis, coronary artery disease and heart failure [12]. It is considered controversial and is not recommended. Currently we have a variety of other obstruction provoking tests, such as the VM [13], the upright position [14], a post-extrasystolic measurement, and inhalation of amyl nitrite [15]. They are mentioned in

Table II. Results for obstruction in the left ventricular outflow tract

\begin{tabular}{|c|c|c|c|c|}
\hline Parameter & $\begin{array}{c}\text { Rest } \\
\text { measurement }\end{array}$ & $\begin{array}{l}\text { Valsalva } \\
\text { maneuver }\end{array}$ & ISDN & $\begin{array}{l}\text { Valsalva } \\
\text { maneuver } \\
\text { and ISDN }\end{array}$ \\
\hline \multicolumn{5}{|l|}{ LVOT peak gradient [mm Hg]: } \\
\hline Median & 16 & 28 & 50 & 59 \\
\hline Interquartile range & $7-26$ & $12-49$ & $12-79$ & $20-87$ \\
\hline Peak LVOT gradient $\geq 30 \mathrm{~mm} \mathrm{Hg} \mathrm{( \% )}$ & 19 & 47 & 62 & 68 \\
\hline Peak LVOT gradient $\geq 50 \mathrm{~mm} \mathrm{Hg}(\%)$ & 0 & 25 & 50 & 58 \\
\hline
\end{tabular}

LVOT - left ventricular outflow tract, ISDN - isosorbide dinitrate. 
the guidelines for the diagnosis and treatment of hypertrophic cardiomyopathy [16]. However, the ISDN test is not mentioned, although it is useful and its effectiveness is established [17]. The novelty of this study is the comparison of the use of the VM and ISDN test either alone or together.

The hemodynamic effect of the VM is caused by a drop-off in left ventricular preload. The test is simple and easy to do, although it does require patient cooperation and is not reproducible. Moreover, when compared to exercise echocardiography, a relatively poor correlation was observed in a study that compared the VM to exercise echocardiography. In this study, the VM also lacked the specificity of exercise echocardiography; however, the results were related to symptom relief following percutaneous alcohol septal ablation [18].

The hemodynamic effect of ISDN is similar to that of the VM and is associated with a drop-off in left ventricular preload; additionally, there is a fall-off of left ventricle afterload. The patient's cooperation is not as important in this test compared to the VM and exercise echocardiography. The usefulness of ISDN was well established in our previous study [14]. This study demonstrates the relatively high sensitivity (76\%) and specificity $(100 \%)$ of the ISDN test compared to the "gold standard" of exercise echocardiography. This study also demonstrates that measurements should be done 5-10 min after application. Although nitrates are not recommended for standard treatment of patients with HCM because they can be potentially harmful, short acting forms, used only for diagnostic tests, are generally safe; the hemodynamic effect, which is undesirable in HCM patients in general, is in this situation required. Our current study demonstrates the utility of both tests for evaluation of LVOT obstructions in HCM. The ISDN test induces an obstruction more often than the VM and also leads to a greater increase in the peak LVOT pressure gradient. Individually, both methods improve detection of LVOT obstructions; however, their utility is substantially increased when used together. The VM alone is cheaper, less time-consuming, feasible in most patients and possibly safer than other provoking tests (including ISDN application), and so it is a reasonable first step in the evaluation of an LVOT obstruction in HCM. Negative results with the VM should be confirmed with other tests. Our experience suggests that the ISDN test is also a good option for assessing LVOT obstruction in HCM. It is important to note that if the ISDN test is negative or borderline-positive, then the VM test should be re-performed during the ISDN test. Exercise echocardiography should be reserved for cases where the results were negative or where clinical uncertainties remain.
A limitation of our study is that although we evaluated consecutive patients, pre-selection of patients related to our center being a tertiary cardiology center could have occurred. Additionally, the study was not designed to describe the morphologic and clinical parameters associated with the development of an LVOT obstruction, which could cause the multivariate analysis to show that the size of the peak rest LVOT gradient was the only independent risk factor for development of an LVOT obstruction. Despite the positive results and the simplicity of both tests, there is still one issue that needs mentioning, which is the usefulness of these tests for prediction of clinical improvement after gradient reduction procedures (i.e. surgical myectomy and alcohol septal ablation). While the number of published studies is limited, they appear to support these procedures. For example, in our previous study, all patients with positive ISDN tests were also positive when tested using exercise echocardiography. Despite the correlation, the indication for gradient reduction procedures should be based on a complex evaluation including clinical symptoms and other echocardiographic findings, and this study focused only on the utility and comparison of two provocation tests. Another issue for discussion is the "cut off" for the peak LVOT gradient as an indicator of significant LVOT obstruction. In our study we used values greater than $30 \mathrm{~mm} \mathrm{Hg}$, as were used in previous publications to distinguish obstructive and non-obstructive forms of HCM. However, because the indication for LVOT reduction procedures is based on a peak gradient that is greater than $50 \mathrm{~mm} \mathrm{Hg}$, we also added this value to our results (Table II). Moreover, the results that compared different tests for this value are similar to a peak gradient that was greater than $30 \mathrm{~mm} \mathrm{Hg}$.

In conclusion, the VM and sublingual spray application of ISDN are useful screening methods for the detection of LVOT obstructions in routine clinical practice. The ISDN test induces an obstruction more often than the VM; however, when ISDN tests are negative, the VM test during ISDN should also be performed.

\section{Acknowledgments}

This study was supported by the project (Ministry of Health, Czech Republic) for conceptual development of research organization 00064203 (University Hospital Motol, Czech Republic), by grant NT 11401-5 from the Internal Grant Agency, Ministry of Health, Czech Republic and by the European Social Fund and the State Budget of the Czech Republic - Project ICRC Human Bridge Support of R\&D teams through formation of new postdoc positions (No. CZ.1.07/2.3.00/30.0023). 


\section{Conflict of interest}

The authors declare no conflict of interest.

\section{References}

1. Houshmand M, Montazeri M, Kuchekian N, Noohi F, Nozar G, Zamani A. Is 8860 variation a rare polymorphism or associated as a secondary effect in HCM disease? Arch Med Sci 2011; 7: 242-6.

2. Veselka J, Duchonová R, Pálenícková J, et al. Age-related hemodynamic and morphologic differences in patients undergoing alcohol septal ablation for hypertrophic obstructive cardiomyopathy. Circ J 2006; 70: 880-4.

3. Zemánek D, Tomašov P, Přichystalová P, Linhartová K, Veselka J. Evaluation of the right ventricular function in hypertrophic obstructive cardiomyopathy: a strain and tissue Doppler study. Physiol Res 2010; 59: 697-702.

4. Zemánek D, Veselka J, Adla T, Šetina M, Ferda J. Uncommon cause of obstruction in the left ventricular outflow tract by a metastasis of adenocarcinoma. Arch Med Sci 2010; 6: 981-3.

5. Maron MS, Olivotto I, Zenovich AG, et al. Hypertrophic cardiomyopathy is predominantly a disease of left ventricular outflow tract obstruction. Circulation 2006; 114: 2232-9.

6. Maron MS, Olivotto I, Betocchi S, et al. Effect of left ventricular outflow tract obstruction on clinical outcome in hypertrophic cardiomyopathy. N Engl J Med 2003; 348: 295-303.

7. Veselka J. Alcohol septal ablation for hypertrophic obstructive cardiomyopathy: is it safe? Catheter Cardiovasc Interv 2009; 74: 520-1.

8. Malek LA, Chojnowska L, Klopotowski M, et al. Long term exercise capacity in patients with hypertrophic cardiomyopathy treated with percutaneous transluminal septal myocardial ablation. Eur J Heart Fail 2008; 10: 1123-6.

9. Shah JS, Esteban MT, Thaman R, et al. Prevalence of exercise-induced left ventricular outflow tract obstruction in symptomatic patients with non-obstructive hypertrophic cardiomyopathy. Heart 2008; 94: 1288-94.

10. Lang RM, Bierig M, Devereux RB, et al.; American Society of Echocardiography's Nomenclature and Standards Committee; Task Force on Chamber Quantification; American College of Cardiology Echocardiography Committee; American Heart Association; European Association of Echocardiography, European Society of Cardiology. Recommendations for chamber quantification. Eur J Echocardiogr 2006; 7: 79-108.

11. Olaf S, Debora B, Ricarda B, et al. Exercise tolerance in asymptomatic patients with moderate-severe valvular heart disease and preserved ejection fraction. Arch Med Sci 2012; 8: 1018-26

12. Vukajlovic D, Milasinovic G, Angelkov L, et al. Contractile reserve assessed by dobutamine test identifies super-responders to cardiacresynchronization therapy. Arch Med Sci 2014; 10: 684-91.

13. Faber L, Heemann A, Surig M, Michalowski Z, Gleichmann U, Klempt HW. Outflow acceleration assessed by continuous-wave doppler echocardiography in left ventricular hypertrophy: an analysis of 103 consecutive cases. Cardiology 1998; 90: 220-6.

14. Dimitrow PP, Bober M, Michałowska J, Sorysz D. Left ventricular outflow tract gradient provoked by upright position or exercise in treated patients with hypertrophic cardiomyopathy without obstruction at rest. Echocardiography 2009; 26: 513-20.
15. Marwick TH, Nakatani S, Haluska B, Thomas JD, Lever HM. Provocation of latent left ventricular outflow tract gradients with amyl nitrite and exercise in hypertrophic cardiomyopathy. Am J Cardiol 1995; 75: 805-9.

16. Gersh BJ, Maron BJ, Bonow RO, et al.; American College of Cardiology Foundation/American Heart Association Task Force on Practice Guidelines; American Association for Thoracic Surgery; American Society of Echocardiography; American Society of Nuclear Cardiology; Heart Failure Society of America; Heart Rhythm Society; Society for Cardiovascular Angiography and Interventions; Society of Thoracic Surgeons. 2011 ACCF/AHA guideline for the diagnosis and treatment of hypertrophic cardiomyopathy. Circulation 2011; 124: e783-831.

17. Zemánek D, Tomasov P, Homolová S, Linhartová K, Veselka J. Sublingual isosorbide dinitrate for the detection of obstruction in hypertrophic cardiomyopathy. Eur J Echocardiogr 2011; 12: 684-7.

18. Jensen MK, Havndrup O, Pecini R, et al. Comparison of Valsalva manoeuvre and exercise in echocardiographic evaluation of left ventricular outflow tract obstruction in hypertrophic cardiomyopathy. Eur J Echocardiogr 2010; 11: 763-9. 